IRA-International Journal of Management \& Social Sciences

ISSN 2455-2267; Vol.07, Issue 03 (2017)

Pg. no. 410-422

Institute of Research Advances

http://research-advances.org/index.php/RAJMSS

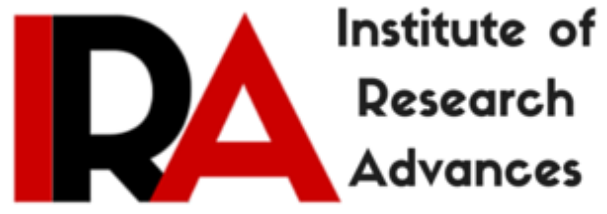

\title{
Influence of Income on Shopping Behavior of Residents and Feasibility of Neighborhood Shops: A Study of Selected South Delhi Localities
}

\section{Gargi Kar Mazumdar}

Shaheed Bhagat Singh Evening College, New Delhi, India.

Type of Review: Peer Reviewed.

DOI: http://dx.doi.org/10.21013/jmss.v7.n3.p2

\section{How to cite this paper:}

Mazumdar, G. (2017). Influence of Income on Shopping Behavior of Residents and Feasibility of Neighborhood Shops: A Study of Selected South Delhi Localities. IRA-International Journal of Management \& Social Sciences (ISSN 2455-2267), 7(3), 410-422.

doi:http://dx.doi.org/10.21013/jmss.v7.n3.p2

(C) Institute of Research Advances

\section{(cc) EY-NC}

This work is licensed under a Creative Commons Attribution-Non Commercial 4.0 International License subject to proper citation to the publication source of the work.

Disclaimer: The scholarly papers as reviewed and published by the Institute of Research Advances (IRA) are the views and opinions of their respective authors and are not the views or opinions of the IRA. The IRA disclaims of any harm or loss caused due to the published content to any party. 


\section{ABSTRACT}

Metro cities of India are going through rapid phase of socio-economic development accompanied with changing standards of living and a rise in purchasing power of population. This increasing expenditure pattern calls for increase in business and commercial outlets in the cities. This is more so noticeable in NCT of Delhi where due to limited availability of urban land for multi functional land use, both planned and unplanned commercial areas are emerging fast to cater to the needs and demands of local population. However, the impact of income as well as other socio-economic factors play an important role in defining the spatial pattern of movement of shoppers which in a way define the survival of neighborhood (both planned and unplanned) shopping centers/ shops. The aim of this research paper is to understand the impact of income in defining the spatial pattern of shopping behavior of the consumer in patronizing the neighborhood shops or markets for various food and non food items. Thus, the present study focuses primarily on identification of shopping patterns / behavior of residents of selected localities in South Delhi. This study is conducted over two economic categories of localities: lower and middle income category locality consisting of areas like Gobind Puri, Gobind Puri Extension and Kalkaji DDA Flat localities; and upper middle and higher income locality consisting of areas like C.R.Park, Kalkaji Main area (excluding DDA LIG, Janta, Slum category flats) and Alakananda. The rationale behind the selection of these two separate socioeconomic areas for the survey is to analyze the inter locality and intra locality comparison of shopping behavior of various income class of population.

The findings of the study favors the feasibility of the local shops in the surveyed localities, since nearness to the market and ease of shopping has encouraged the survival of the local shops/markets operating in the residential colonies especially for food items. However apart from income levels, standard of living is also influencing the shoppers behavior and growing trend of shopping from Malls and Plazas is also noticed showing changing preference of shoppers for well established market areas than local shops especially for non food items. Through GIS based mapping, the movement of shoppers for both food and non food items is traced and specific suggestion are given regarding the changing land use under commercial activities in the survey areas. Area specific suggestions are given in the light of Master Plan of Delhi 2021.

Key Words: Shopping behavior, Trend surface analysis, PCA, neighborhood shops, spatial pattern of shoppers movement, feasibility of local shops/ markets, changing preference of shoppers.

\section{Introduction}

Increasing urbanization provides a base for economic development and the challenge being faced is how to make this growth sustainable, efficient and equitable. In the last few decades, in metro city like Delhi, the rapidity of population growth has become synonymous with urbanization. The rapid expansion of urban areas due to rise in population and economic growth is increasing additional demand on already limited supply of land thereby causing growth in mixed land-use, which is often unplanned and haphazard. The city landscape in response to the changing dynamics of urban economic base is going through phases of reconstruction and restructuring, which brings into debate the question of feasibility of incorporating those structural changes as integral part of urban economic planning. The sustainable economic development is an approach to economic planning that attempts to foster economic growth while preserving the quality of the environment for future generations. The cities are believed to be the engine of economic growth and provide jobs, services and assurance of a better quality of life. Therefore, the cities of developing countries face the twin problem of urban planning and sustenance. While planning requires restriction of land-use under proposed guidelines/ recommendations; the economic structure/ avenues favor a free use of urban land. Consequently, cities of today are going through a phase of physical restructuring to support the economic activities. 
The present study focuses primarily on identification of shopping patterns / behavior of residents of selected localities in determining the feasibility of promoting commercial shops in residential areas, since the built environment itself is a spatial manifestation of socio-economic behavior of population.

\section{Literature Review}

With growing concerns about the sustainability of urban environment especially in its economic terms, a lot of work has been done related to this field. Some of the following literature have been reviewed for the present paper such as by Jones, G. W. (1983), Berry, B.J.L. (1976), Preston, S. (1984), Pathak, C. R. (1975) and Alam, S.M.; Rao, R. M. and Gopi, K. N. (1974) are to name a few. The growth and spatial structure of Indian cities was also identified by Brush, J. E. (1977). The mechanism and dynamics of urbanization were observed by Munshi, S. K. (1975). Bose, A. (1978) traced the trends and patterns of Indian urbanization during twentieth century along with its dynamics of city growth and development. MacLachlan, D.; Dickson, L. and John, P. (1990), have dealt with the urban environmental sustainability in the light of shopping behavior as a determinant of social distance. Mackenbach et al (2016) in their study examined the socio-economic differences in physical commuting, and evaluated the impact of urban land-use and public transport policies on commuting in Wellington, in New Zealand. Results indicated high income individuals were more likely to commute actively than individuals on low income.

A comprehensive treatment of hedonism and culture on shopping behavior reflecting two distinct form of consumer: hedonic and utilitarian are thought to be the determinants of the purchasing behavior of shoppers (Kaul, 2006). Gayler, (1979), studied the spatial behavior pattern of consumer and its relation to the retail structure of an area through cognitive behavioral approach. However, a geographers approach to the study of the spatial distribution, spatial interaction and spatial regularity to analyze the urban economic environment by concentrating on the economic indicators of sustainable economic development is still at nascent stage.

Thus, the present work is focused upon the study of urban economic environment through shopping behavior as an indicator of recording changing spatial preferences for shopping trips and restructuring of urban built up area as a result of continuance/discontinuance of shopping destinations.

\section{Methodology}

In this study, which is a sub-part of a larger research work, both primary and secondary data, have been used. Primary household data was collected in the year 2006 and 2007 from field survey through selfstructured questionnaire based upon the selected indicators for a larger research work. That data has been supported with some field survey done in 2015 to study the urban land use of the area. Also corresponding secondary data for South Delhi, Zone F from published sources for 2011 has been used. Research hypothesis have been formed and have been tested through chi-square test for various aspects related to the shopping behavior of residents living in areas dominated by varying income group population. Through GIS based mapping, the movement of shoppers for both food and non food items is traced and specific suggestion are given regarding the changing land use under commercial activities in the survey areas.

The data is tabulated by cross classifying the number of households into three income levels: Lower Income Group (<10,000), Middle Income Group (10,000- 30,000) and Higher Income Group (>30,000).

\section{Aim and Objectives}

The aim of this research paper is to understand the impact of income in defining the spatial pattern of shopping behavior of the consumer in patronizing the neighborhood shops.

The important objectives of the study are:

- To find out the influence of income in determining the distances traveled for food and nonfood items in the study area. 
- To find out the influence of income in determining the frequency of shopping trips measured through the purchasing activity for food and non-food items in the study area.

- To analyze the determinants of shopping behavior of various income groups in the study area.

- To study the shopping pattern through trend surface analysis.

- To give suggestions, if any, to plan for the feasibility of local shops/ super markets/ shopping plazas in the neighborhood for sustainable economic development of the area.

\section{The Study Area}

To carry out the research, the study area is focused to Zone F covering South District of Delhi. \{DDA (area planning): 2010\}. Fig: 1. It is one of the 9 districts of NCT of Delhi (Census of India 2011). In 2012, two more districts have been added taking the count of total districts to eleven now in Delhi.

In terms of area, South district is the third largest district of Delhi, which spreads over 249 Sq. kms. and covers 16.7percent of the total area of NCT of Delhi. The reason for increasing concentration of population in South Delhi is the co-existence of a number of industries in Okhla industrial area, super markets, shopping plazas and offices and residential complexes for all socio-economic classes.

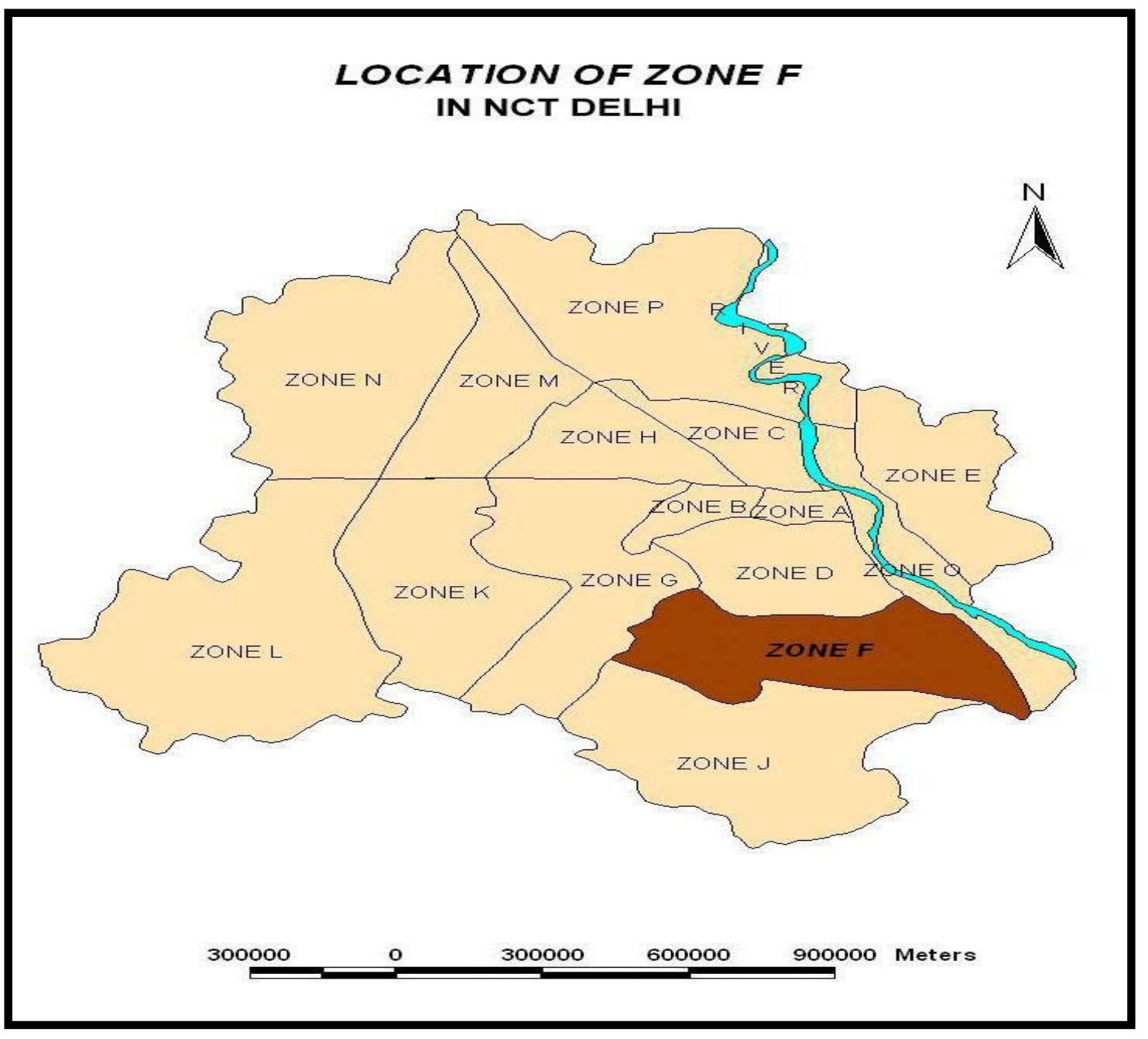

Figure: 1 Source: DDA (area planning): 2010 
To conduct the field survey, a pilot survey was carried out first. It was decided that MCD ward number 9 and 10 are occupied by high, middle and low-income group of population exhibiting a highly diverse land-use pattern, where inter and intra sample variations are expected to be maximum. Out of 5,954 households in the study area of South Delhi, under Zone F, a sample size of 178 households is calculated which came to be significant at 0.05 level of significance.

The study area is divided into two economic categories of selected localities: lower and middle income category localities consisting of areas like Gobind Puri, Gobind Puri Extension and Kalkaji DDA Flat; and upper middle and higher income localities consisting of areas like C.R.Park, Kalkaji Main area (excluding DDA LIG, Janta, Slum category flats) and Alakananda. The rationale behind the selection of these two separate socio- economic areas for the survey is to analyze the inter locality and intra locality comparison of shopping behavior of various income class population.

\section{Hypothesis}

Since the study is operational in research, sets of hypothesis related with sets of theoretical assumptions are formulated which are analyzed under results and discussions.

\section{Results and Discussions}

1. To achieve the $\mathbf{1}^{\text {st }}$ objective a number of hypothesis are made to find out the significance of relationship between the income levels and the distances traveled for the shopping of food and non-food items.

I. The influence of short distance $(1.0-2 \mathrm{kms})$ on the shopping of non-food items in the two sets of localities within lower and higher income group.

Hypothesis 1: Within lower income group, there is less distances traveled for non- food items.

Lower Income Group: A positive relationship is established between the short distances traveled for non-food items and the level of income with 95\% confidence level. Since the requirement for nonfood items is limited within lower income group, only occasionally people in this income level are traveling to longer distances.

Hypothesis 2: Within higher income group, there is less distances traveled for non- food items.

Higher Income Group: As the requirement for non-food items is high within higher income group especially for frequently required items like fuel, stationary items, gas etc., therefore shorter distance travel is more dominant. This is confirmed by the rejection of null hypothesis at 0.05 level of significance suggesting the existence of a significant relationship between the higher income and shorter distances traveled for non-food items.

II. The influence of longer distance (4 kms and above) on the shopping of non-food items in the two sets of localities within lower and higher income group.

Hypothesis 3: Households from lower income group travel greater distances for shopping of nonfood items.

Lower Income Group: The analysis of the lower income group accepts the null hypothesis at 0.05 level of significance therefore establishing a negative relationship between the distances traveled and income levels. Since the requirement of non food items is limited, therefore people in this income level occasionally travel longer distances mainly for selected non-food items like furniture or 
electrical gadgets, especially when they do not find those items in their nearby markets at reasonable/ discounted rates.

Hypothesis 4: Households from higher income group travel greater distances for shopping of nonfood items.

Higher Income Group: At $95 \%$ level of confidence, a positive relation has been established since households from this income group very frequently visit shopping complexes, open markets, plazas and malls located at distances within $4 \mathrm{kms}$ and above, for non-food items like clothes, accessories, home décor items, jewelry, electrical gadgets, furniture etc.

III. The influence of short distances (less than $0.5 \mathrm{~km}$ ) on the shopping of food items in the two sets of localities within lower and higher income group.

Hypothesis 5: Within lower income group, there is less distances traveled for food items.

Lower Income Group: At 0.05 level of significance, the null hypothesis is rejected thus, establishing a significant relationship with $95 \%$ confidence level, between the short distances traveled for the shopping of food items by lower income group, irrespective of the socio-economic status of the locality. This further suggests that nearness/ availability of food items at shorter distances is a deciding factor for the shopping behavior for food items.

Hypothesis 6: Within higher income group, there is less distances traveled for food items.

Higher Income Group: Even the higher income group households prefer to visit the nearby shops more frequently to buy food items because of the presence of a number of local shops/ departmental stores providing a variety of food items in the vicinity of the localities. Thus, nearness emerges again as a deciding factor to determine the shopping behavior of the higher income group for food items, which is also established by the rejection of null hypothesis at 0.05 level of significance.

2. To realize the 2nd objective, hypothesis testing is done to determine the significance of relationship between the income levels and the frequency of shopping trips for food and non-food items.

I. The influence of higher frequency of trips (less than 7 days) on the shopping of food items in the two sets of localities within lower and higher income group.

Hypothesis 7: Households from lower income group have greater mobility or frequency of trips for shopping of food items.

Lower Income Group: Since higher percentage of surveyed households in this income group are on rented accommodation with limited storage facilities; more frequent trips are made for shopping of food items. This is established by a significant relation with lower income group and the higher frequency of shopping trips at $95 \%$ confidence level. 
Hypothesis 8: Households from higher income group have greater mobility or frequency of trips for shopping of food items.

Higher Income Group: The higher socio-economic class mostly supportive of joint families with higher degree of food requirement shows a higher frequency of visits for food shopping. Hence, a positive relationship between higher income group and higher frequency is established with $95 \%$ level of confidence.

II. The influence of lower frequency of trips (16 to 183 days) on the shopping of non-food items in the two sets of localities within lower and higher income group.

Hypothesis 9: Households from lower income group have lower frequency of trips for non- food items.

Lower Income Group: The lower income group with lower requirement of non-food items prefers to visit the markets within a month to six months time showing occasional visits for selected nonfood items as per their needs. Hence, a significant relationship has been depicted between lower income group and lower frequency of trips with $95 \%$ level of confidence.

Hypothesis10: Households from higher income group have lower frequency of trips for non- food shopping trips.

Higher Income Group: At 0.05 level of significance, the null hypothesis is rejected, as the households from higher income group also prefer to travel occasionally for buying non-food items like furniture, clothes, electrical gadgets etc. but the only difference is that their expenditure on nonfood items per trips are much higher than lower income groups.

3. To attempt the 3rd objective the determinants of shopping behavior have been analyzed, the analysis of bi-variate correlation coefficient on key variables of shopping activity are showing the following results:

Frequency of Trips for Food Items: The trips made for food items are governed by the ease by which the required products can be bought. Since, both the set of localities have neighborhood shops within a range of $0.5-2 \mathrm{kms}$, the trips for perishable food items are frequently made. The data analysis shows that $50 \%$ households from LMIC localities frequently i.e. within less than 7 days visit the markets for buying food items, while $47 \%$ households from UMHIC localities visit the markets within 7 days' time period. Many households from LMIC localities prefer to go to the neighborhood stores for their regular fooditems. This is mainly because of the services provided by super market stores, and also because of the feeling of attachment or loyalty as shown by co-relation value of $(+0.80)$. The higher frequency of trips for food items also has a strong correlation with joint families with kids and elderly as noticed in UMHIC localities.

Frequency of Trips for Non-Food items: In UMHIC areas, the households with joint family system visit the shops on a regular basis i.e. within a fortnight. The significant point is that the residents especially the higher income groups from both set of localities prefer to visit plazas and malls beyond 4 kms, within a period of six months for better quality and branded non-food items like home décor, furniture, accessories, appliances, jewelry etc. Within a fortnight to month shopping trips are also made to buy regularly required non-food items like toiletries, stationary etc. Shoppers even from the LMIC areas 
due to the influence of growing urbanism prefers to visit malls/ plazas for shopping of discounted nonfood items.

Distances Traveled for Food Items: The study shows that around 74\% of households from the LMIC areas prefer to go to the nearby shops/ markets within $0.5 \mathrm{~km}$ radius for buying different type of food items. However, from the UMHIC areas only about $41 \%$ of households shop within $0.5 \mathrm{~km}$ radius for food items. This is mainly because the LMIC localities have many shops/ markets in their close vicinity selling food items.

Distances Traveled for Non-Food Items: The comparative study shows that $72 \%$ households from LMIC and $66 \%$ households from UMHIC localities travel distances within $0.1-2 \mathrm{kms}$ for non-food items. The income category of less than 10,000 in the UMHIC localities have $74 \%$ of households traveling shorter distances within $0.1-2 \mathrm{kms}$ is slightly lower than LMIC, which has about $79 \%$ of households because few households are traveling even further distances to shop for quality items.

To achieve the $4^{\text {th }}$ objective, a trend surface analysis is attempted on the basis of PCA scores. PCA scores identified certain phenomena depicting the spatial pattern of the shopping behavior.

Trend Surface Analysis I: The spatial pattern of the dimension of PCA I is shown by the iso-lines drawn on the basis of PCA component scores. The phenomenon of 'Distances and Frequency of Trips to Commercial Centers, Malls and Plazas from Affluent Localities'(Fig: 2) is showing a concentration of values in C.R. Park, Alakananda and Kalkaji Main area and covering a wider area around the above three localities. Most surveyed households from these localities confirmed going to markets even at farther distances mainly for buying better quality/ branded/ variety products. On the other hand DDA flats and Gobind Puri/ Gobind Puri Extension show negative component scores on this aspect of shopping behavior. Thus, the study area has been clearly divided into almost two parts regarding this shopping behavior: the north and west with households from Kalkaji main area, C.R.Park, Alakananda having higher preference for it and the households from south eastern part from Gobind Puri and DDA flats showing a lack of this aspect of shopping behavior. 
PCA I: Distances and Frequency of Trips to Commercial

Centers. Malls and Plazas from Affluent Localities.

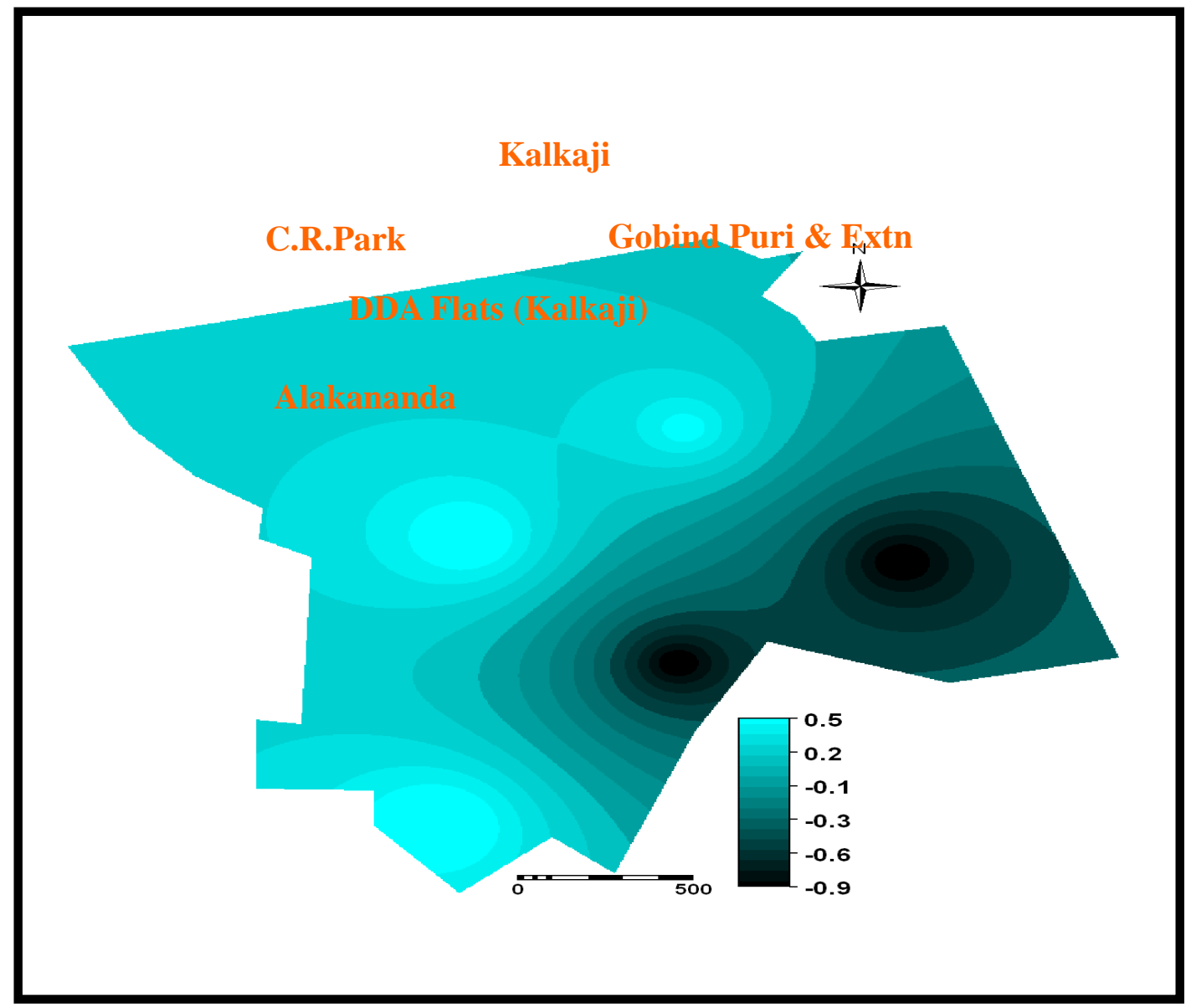

Trend Surface Analysis II: The spatial pattern of the dimension of PCA II is represented through isolines drawn on the basis of PCA II component scores. The phenomena of 'Shopping for Nearness and Cost effectiveness by Middle Class' shows a high concentration of values in C.R.Park, Kalkaji DDA Flats and Main Kalkaji area covering a wider area in an around C.R.Park and a smaller part in Kalkaji DDA Flats. As C.R.Park is mainly occupied by Bengali speaking population and their demands of food items especially for products like fish, sweets, etc are easily met out by the closer by markets, this locality shows preferences for nearby shops. Even a very small area in Kalkaji DDA flats is also showing the same phenomena. And although Kalkaji main area shows slightly higher values than Gobind Puri/ Gobind Puri Extension, both of the areas have some households selecting neighborhood markets for its cost effectiveness for buying food and non-food items. Thus, the study area has been clearly divided into almost three parts regarding this shopping behavior: the north, west and south east areas from C.R.Park, Kalkaji DDA Flats and Main area having dominance of it while the households from eastern part from Gobind Puri and southern part from Alakananda are showing a lack of this aspect of shopping behavior. However, this phenomenon seems to be spatially more wide spread than the PCA I. 
PCA II: Shopping for Nearness and Cost effectiveness By Middle Class

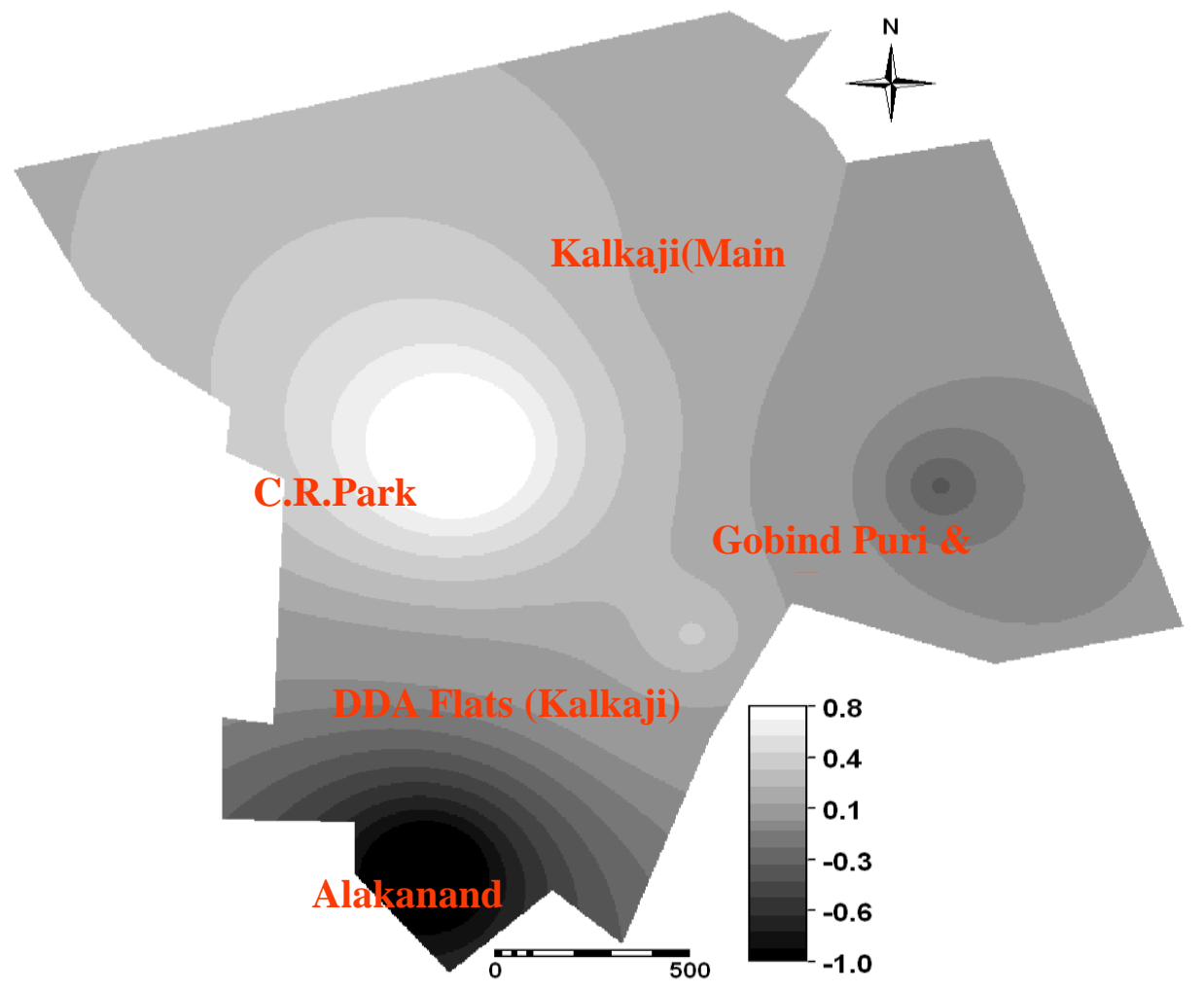

Trend Surface Analysis III: The spatial pattern of the dimension is brought about by the component score on PCA III of 'Selection of Stores for Better Quality by Employed Females' which shows a higher concentration of values in Kalkaji Main area and DDA Flats. While the female worker are employed in relatively better income category due to their education in Kalkaji main area, the DDA flats (especially Slum category, Janta category flats) have females employed with less pays due to lesser education. Thus, the employed females visit the stores according to their level of income, family requirement and the cost of travel with a view to avail the good variety and better quality items. The same is also true to a lesser extent in Alakananda. But in Gobind Puri/ Gobind Puri Extension less educated non working females are not patronizing stores as such due to less income. In C.R. Park, the surveyed households have a dominance of elderly people with high dependence ratio; therefore, they do not play much role in determining the shopping behavior of the area. However, spatially this phenomenon is less prevalent than PCA II. 


\section{PCA III: Selection of Stores for Better Quality By Employed Females}

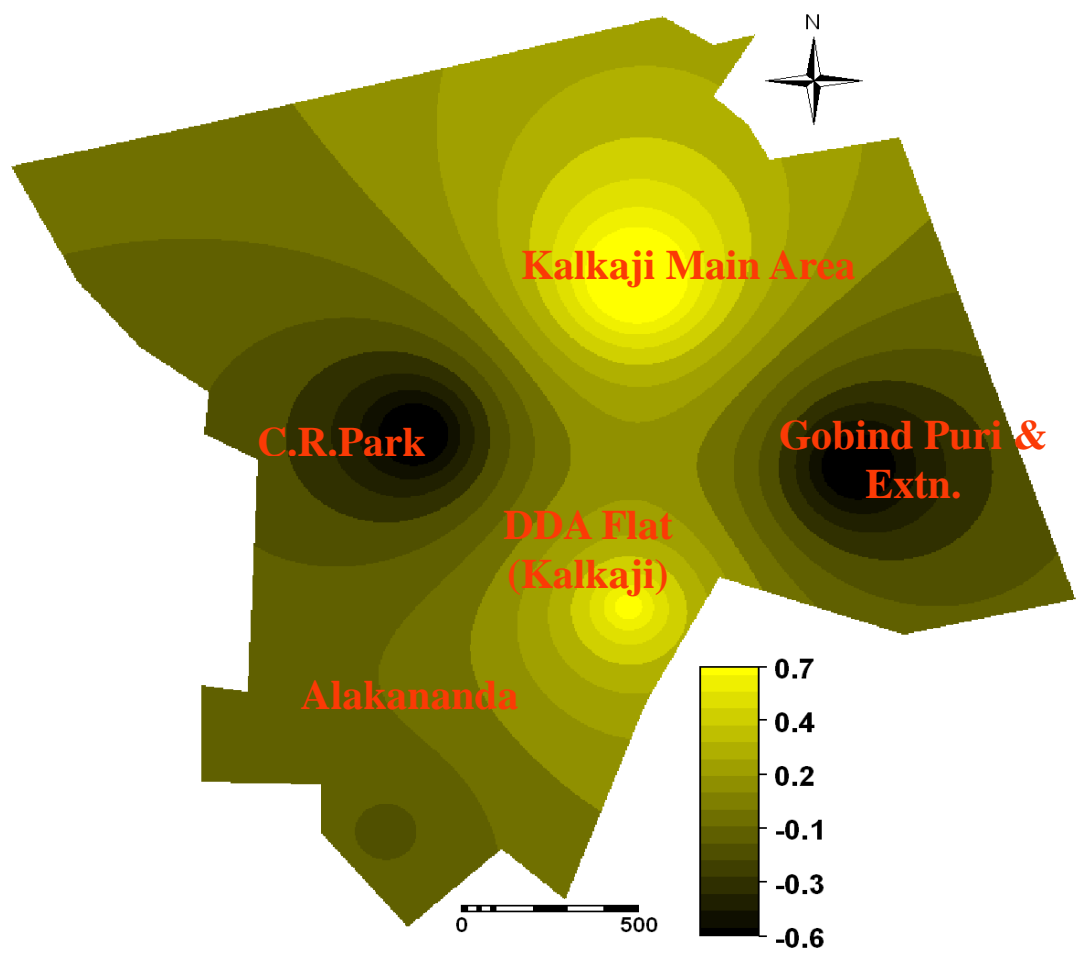

Trend Surface Analysis IV: The spatial pattern of the dimension is analyzed on the basis of component score of PCA IV of 'Loyalty and Trust of Shoppers' which is shown by higher concentration of values in and around Gobind Puri/ Gobind Puri Extension and Kalkaji Main area. Since this phenomenon is a trait of shoppers who patronize shopping centers through regular visits, the congested areas of Gobind Puri/ Gobind Puri Extension and Kalkaji main area, stand out prominently on this aspect. However, few households from C.R.Park also prefer to shop from stores/ markets that they trust upon for the quality of available products, hence are loyal towards such stores/ markets. However, moving away from these two areas towards the south west, Kalkaji DDA Flats and Alakananda shows the lack of this phenomenon, since Kalkaji DDA flats (including Slum and Janta category flats) have lower/ middle income groups who choose stores for cost effectiveness and variety. While Alakananda consisting of affluent population patronizes stores with branded quality items found in super stores, plazas and malls. However, this phenomenon is wide spread in comparison to PCA III highlighting the most significant aspect of the shoppers of the study area i.e. the faith and loyalty attached to the nearby shops/ markets/ super stores irrespective of the socioeconomic status of the area. 
PCA IV: Loyalty and Trust of Shoppers

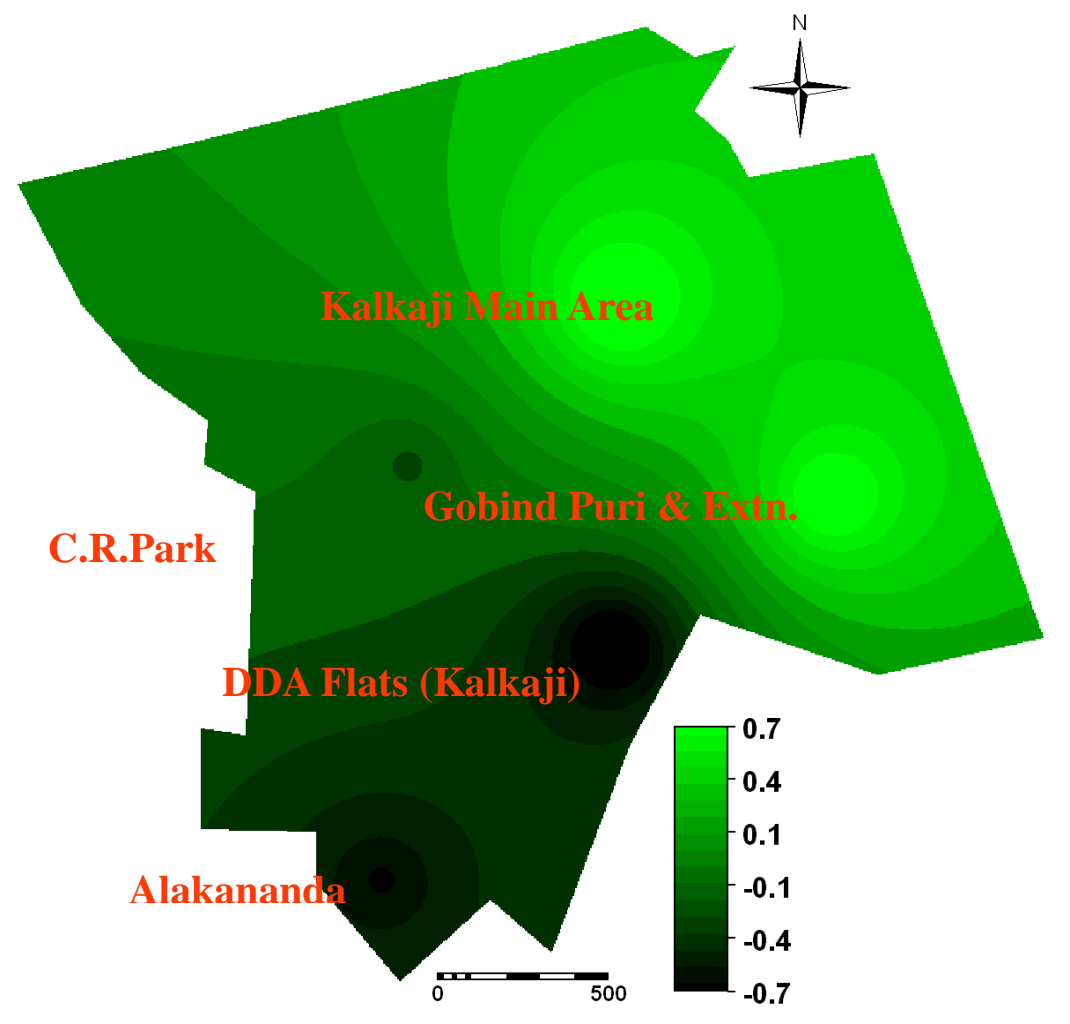

To achieve the $\mathbf{5}^{\text {th }}$ objective, some suggestions have been given to plan for the feasibility of the existence/ survival of local shops/ super markets/ shopping plazas in the neighborhood for the sustainable economic development of urban environment of the study area in Delhi.

The survey results shows that nearness to shopping centers is the most significant aspect of the study as the households prefer to shops from their neighborhood markets/ local shops/ super markets/ plazas mainly for regularly required food and non-food items as per their income levels. Hence, MPD-2021's decision of permitting local shops/ stores operating from ground floor of residential units seems to be justifiable. However, the main concern is that with this permission there are chances that more local stores/ shops will be opened at residential premises leading to lot of congestion, crowding and rising pollution levels especially in LMIC localities.

Since the mixed land use cannot be avoided in Delhi, it is better to be worked out with the help of public private partnership. This includes checking illegal encroachment upon already congested narrow roads, providing parking space at least for two wheelers, encouraging underground parking for the new commercial set ups and granting of easy and short term loans for the up gradation of the 
existing local shops/ markets. Thus, to manage the urban economic environment of a metropolitan city like Delhi, apart from the strict land legislation policies and institutional reforms, the role of public-private partnership like RWAs (Residents Welfare Association) should be identified in promoting the mixed land use plan as suggested by MPD-2021.

Thus, the present study has focused upon primarily on identification of shopping patterns / behavior of residents of selected localities in determining the feasibility of promoting commercial shops in residential areas, since the built environment itself is a spatial manifestation of socio-economic behavior of population.

\section{Reference and Bibliography}

1. Alam, S. M.; Rao, R. M. and Gopi, K. N. (1974), "Trends and Patterns of Metropolitan Development in India", Occasional Paper No. 3, Center for Urban Research, Osmania University, Hyderabad.

2. Bartone, C.R. 2001. "Urban Environmental Management and the Poor." Environmental Strategy Background Paper, Urban Development, Infrastructure Group. Washington, D.C.: World Bank.

3. Bawa, K. and Ghosh, K (1999) "A Model of Household Grocery Shopping Behavior", Marketing Letters, Kluwer Academic Publishers, The Netherlands.

4. Bell, S. and Morse, S. (1999), "Sustainability Indicators: Measuring the Immeasurable", published by Earthscan, London.

5. Berry, B. J. L. (1976), “Urbanization and Counter Urbanization”, Sage Publication, Beverly Hills, Calif.

6. Bose, A. (1978), “India's Urbanization 1901 - 2001, Tata McGraw Hill Publishing Company Ltd., New Delhi.

7. Brush, J.E. (1977), “ Growth and Spatial Structure of Indian Cities”, Indian Urbanization and Planning, Allan G. Noble and A. K. Dutta (Eds.) Tata McGraw Hill Publishing Co., New Delhi.

8. Gayler, H. J. (1979), "Social Class and Consumer Spatial Behaviour: Some Aspects of Variation in Shopping Patterns in Metropolitan Vancouver, Canada", Transactions of the Institute of British Geographers, 5, 4 (1980), 427-445.

9. Indian State Forest Report, 2009.

10. Jones, G. W. (1983), "Structural Change and Prospect for Urbanization in Asian Countries", Papers of the East West Population Institute, East West Center, Honolulu.

11. Kaul, S. (2006) "Hedonism and Culture: Impact on Shopper Behavior", Research and Publication, Indian Institute of Management Ahmedabad, India.

12. Llyod, R. and Jennings, D. (1978) " Shopping Behavior and Income: Comparisons in an Urban Environment”, Economic Geography, published by Clark University (USA).

13. MacLachlan; Douglas, L and Dickson, J, P. (1990), " Social Distance and Shopping Behavior", Journal of the Academy of Marketing Science, 18 (2): 153-161.

14. Master Plan of Delhi -2021, (2007), Delhi Development Authority, Ministry of Urban Development, Controller of Publication, Delhi.

15. Meiti, S. and Agarwal, K. P.(2005), "Environmental Degradation in the Context of Growing Urbanization- A focus on the Metropolitan Cities of India", Journal of Human Ecology, KRE publisher, Delhi.

16. Munshi, S. K. (1975), "The Nature of Urbanization- A Review", Geographical Review of India, 37:4, 287-299.

17. Preston, S. (1984), "A Path Model of Residential Stress and Inertia among Older People", Urban Geography, 5, 146-64..

18. Zonal Development Plan, Zone F, Delhi Development Authority (1998), Ministry of Urban Affairs and Employment, Department of Urban Development, Delhi. 